Research Paper

\title{
Analysis of Differential Expressions of Long Non-coding RNAs in Nasopharyngeal Carcinoma Using Next-generation Deep Sequencing
}

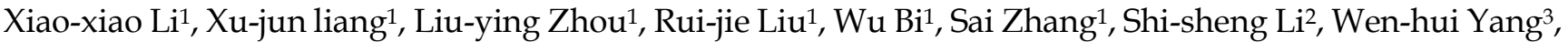 \\ Zhu-chu Chen ${ }^{1}$, Xin-ming Yang ${ }^{2 \bowtie}$, Peng-fei Zhang ${ }^{1 凶}$ \\ 1. Key Laboratory of Cancer Proteomics of Chinese Ministry of Health, Xiangya Hospital, Central South University, Changsha, Hunan, 410008, P.R. China \\ 2. Department of Otolaryngology Head and Neck Surgery, The Second Xiangya Hospital, Central South University, Changsha, Hunan,410011, P.R. China \\ 3. International College, Guangdong University of Foreign Studies, Guangzhou, Guangdong, 510420, P.R. China \\ $\triangle$ Corresponding authors: Pengfei Zhang, M.D., Ph.D., Professor and Vice Director, Key Laboratory of Cancer Proteomics of Chinese Ministry of Health, \\ Xiangya Hospital, Central South University, Changsha, Hunan, China. Tel: 86-731-84327239; Fax: 86-731-84327608; E-mail: zhangpf690421@csu.edu.cn and \\ Xin-ming Yang, M.D., Professor and Director, Department of Otolaryngology Head and Neck Surgery, The Second Xiangya Hospital, Central South University, \\ Changsha, Hunan, China. Tel.: +86-(0)731-84213972; Fax: +86-(0)731-85533525; E-mail:x16y2013@outlook.com \\ ( $)$ Ivyspring International Publisher. This is an open access article distributed under the terms of the Creative Commons Attribution (CC BY-NC) license \\ (https://creativecommons.org/licenses/by-nc/4.0/). See http://ivyspring.com/terms for full terms and conditions.
}

Received: 2017.10.25; Accepted: 2018.03.13; Published: 2018.04.30

\begin{abstract}
Background: Little knowledge about long non-coding RNAs(IncRNAs) in nasopharyngeal carcinoma (NPC) has been acquired.

Methods: Next-generation sequencing was applied in 7 cases of NPC tissues and 7 cases of normal tissues in nasopharynx. PLEX, CNCl and CPAT soft-wares were used to predict novel IncRNAs. Real-time Quantitative PCR (qPCR) further validated the data in 20 cases of NPC tissues and 14 cases of normal tissues. Then the cis-regulators and trans-regulators and potential biological functions together with pathways were predicted by Bioinformatics.

Results: Totally, 4248 novel IncRNAs were found to be expressed in our samples. And 2192 IncRNAs and 23342 mRNAs were considered to be differentially expressed in NPC. Among the results, 306 IncRNAs and 4599 mRNAs were significantly up-regulated, whereas 204 IncRNAs and 2059 mRNAs were significantly down-regulated, respectively. Moreover, 62 IncRNAs trans-regulated genes were involved in Epstein-Barr virus (EBV) infection pathway in our study. Jun proto-oncogene (JUN), which was related to a cis-regulator IncRNA RP4-794H19.1, was enriched in cancers and involved in Tumor Necrosis Factor (TNF) signaling pathway, might play a key role in NPC.

Conclusion: These findings broadened the IncRNAs landscape of NPC tissues and shed light on the roles of these IncRNAs, which might be conducive to the comprehensive management of NPC.
\end{abstract}

Key words: Nasopharyngeal carcinoma, RNA sequencing, Long non-coding RNAs, Bioinformatics analysis, QPCR

\section{Introduction}

Globally, about 86,500 cases of nasopharyngeal carcinoma (NPC) were reported in 2012. NPC was a mortal disease prevailing in South-east Asia and North Africa [1]. In China, the standardized mortality rate was $0.78 / 10^{5}$ issued in 2013[2]. NPC arose as a result of its various genetic susceptibility, environmental or random factors and Epstein-Barr virus
(EBV) infection[3]. Albeit researchers were at full tilt unraveling the tumorigenesis and the pathways, we seldom knew them yet.

Long non-coding RNAs(lncRNAs) previously were considered as "transcriptional noise", which accounted for at least $75 \%$ of DNA transcripts[4]. Generally speaking, lncRNAs are longer than 200 
nucleotides and short of protein-coding capacity, with lacking of open reading frame (ORF) $[5,6]$. Encyclopedia of DNA Elements (ENCODE) Project Consortium issued at least 120,000 transcripts that served as lncRNAs in the human genome[7]. Now lncRNAs have been validated that it played a gorgeous role in regulating gene expression at various levels to affect cellular homeostasis, including proliferation, survival, migration and genomic stability[4]. Up-to-date evidences laid bare that the aberrantly expressed lncRNAs always were relative to the development and progression of cancers[8-11]. Given the eagerness to better understand NPC, many researchers took the cutting-edge lncRNAs to the spotlight.

The lncRNAs research in NPC usually resorted to Microarray and lncRNA-protein-based relationship technology [12-16], or at cell level[17]. Microarray was a high-throughput sequencing, but it was limited by countable numbers of lncRNAs, and all the probes were already known, which was the reason for refraining the technology from discovering novel lncRNAs. Despite LncRNA-protein-based relationship technology as RNA Immunoprecipitation (RIP)-chip and RIP-sequencing, its antibody specificity made the research focus on one point. The next-generation deep sequencing took its advantages in discovering massive exiting and novel lncRNAs[18]. Here, we applied the next-generation deep sequencing to provide a comprehensive view for insights into NPC tissues.

\section{Materials and Methods}

\section{Samples collection}

There were 20 cases of NPC tissues and 14 cases of normal tissues collected by the second Xiangya Hospital of Central South University. All sample tissues were confirmed by histopathological examination in the second Xiangya Hospital of Central South University. This study was approved by the Ethical Committee of Xiangya Hospital, Central South University. All patients had voluntarily signed a written consent before samples were collected. The acquired tissue samples were placed into liquid nitrogen immediately and then were transferred to a $-80^{\circ} \mathrm{C}$ refrigerator.

\section{RNA extraction}

The abstraction of total RNAs derived from 20 cases of NPC tissues and 14 cases of normal tissues, using TRIzol (Life Technology, California, USA) according to the guideline protocol. The sample tissues were placed in $2 \mathrm{ml}$ RNA-free EP tube that grinded with four $4 \mathrm{~mm}$ steel balls in TissueLyser LT (QIAGEN, Dusseldorf, Germany). The purity and concentration of RNAs were measured by OD260/280 readings shown on DeNovix DS-11+ (DeNovix, Delaware, USA), which ranging from 1.8-2.2 were kept. RNAs integrity was qualified by standard denaturing agarose gel electrophoresis.

\section{cDNA synthesizing and Real-time Quantitative PCR(qPCR) analysis}

The first strand of cDNA was synthesized by Promega GoScript (Promega, Madison, USA) with 2 $\mu \mathrm{g}$ total RNA. The qPCR setting 40 cycles of amplification was performed on GoTaq qPCR Master Mix (Promega, Madison, USA) on LightCycler 480 II QPCR System (Roch, Basel, Switzerland). $\beta$-actin served as a reference, and relative-expression levels of lncRNAs were quantified through $2(-\Delta \Delta \mathrm{Ct})$ methods.

\section{Library preparation for IncRNA sequencing}

There were 7 cases of NPC tissues and 7 cases of normal tissues for RNA sequencing. Total RNAs were abstracted as previously, strand-specific RNA-seq Libraries were generated with TruSeq ${ }^{\circledR}$ RNA LT Sample Prep Kit v2 (Illumina, CA, USA) following the handbook, subsequently the Ribo-Zero Gold kit (Illumina, CA, USA) was used for the removing of rRNA, and then the fragmentations of RNAs were harvested. RNA fragmentations were used to synthesize double-stranded cDNA with substituting dUTPs for dTTPs in the second strand cDNA synthesis. Next, double-stranded cDNA were added to A-tailed and ligated to adaptors. Finally, PCR amplification was performed to enrich cDNA libraries. PCR products were qualified by Quant-iT ${ }^{\mathrm{TM}}$ PicoGreen ${ }^{\circledR}$ dsDNA Assay Kit (Life Technology, MA, USA) for RNA sequencing.

\section{RNA sequencing}

Sequencing was performed on an Illumina Hiseq 2500 instrument (Illumina, CA, USA) with the TruSeq PE Cluster Kit v3-cBot-HS (Illumina, CA, USA).

\section{Results}

\section{The prediction of novel IncRNAs}

Transcripts were aligned with databases, such as the Kyoto Encyclopedia of Genes and Genomes (KEGG), Clusters of Orthologous Groups (COG) and Swissprot Database, then the mapped transcripts (mRNA) were dropped. Subsequently, transcripts annotated in the lncRNA library (Ensemble) were also cast away. The remaining transcripts were inputted into three Coding Potential Calculator soft-wares (PLEX, CNCI and CPAT) to predict coding and non-coding sequences. We kept the 4248 transcripts which overlapped in three calculation methods, serving as novel lncRNAs. CNCI-CPAT, CPAT-PLEK 
and PLEK-CNCI overlapped numbers were 237, 26 and 401, respectively. Venn Diagram of predicted novel lncRNAs was shown in Figure 1.

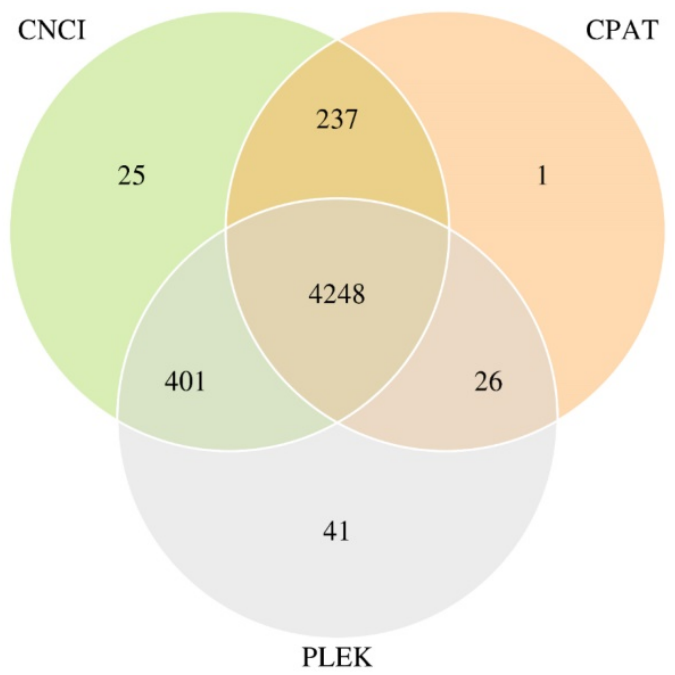

Figure 1: Venn Diagram of predicted novel IncRNAs with three the Coding Potential Calculator soft-wares.

\section{The landscape of differential expressions of IncRNAs and mRNAs sequencing in NPC and normal tissues}

In total, 2192 lncRNAs and 23342 mRNAs were considered to be differentially expressed in NPC. Among the results, 204 lncRNAs and 2059 mRNAs were significantly down-regulated, and 306 lncRNAs and $4599 \mathrm{mRNAs}$ were significantly up-regulated $(\geq 2$ fold change, FDR $<0.05)$. Compared with normal tissues, OSER1-AS1 (fold change: -4.54 , FDR $<0.05$ ) and MUC4 (fold change: -8.00, FDR $<0.05$ ) were the most down-regulated lncRNA and mRNA, as opposed to the most up-regulated lncRNA and mRNA, which were RP11-624L4.1 (fold change: 4.35, FDR<0.05) and XLOC.42541.1 (fold change:13.20, FDR $<0.05)$, respectively. The volcano plot of

differential expressions of lncRNAs and mRNAs were displayed in Figure 2. Heat maps of differential expressions and hierarchical clustering of lncRNAs and mRNAs in NPC and normal tissues were demonstrated in Figure 3.

\section{RNA sequencing data validation by $q P C R$}

Seven lncRNAs were sifted through on the basis of differentially expressed lncRNAs prediction for validating RNA sequencing data, which were lncRNA-NR2F2 antisense RNA1(NR2F2-AS1) (fold change:-3.2), lncRNA-family with sequence similarity 95 member C(FAM95C) (fold change:-3.3), lncRNAlong intergenic non-protein coding RNA 1106 (LINC01106) (fold change:-3.7), IncRNA-CH507513H4.6 (fold change:3.8), lncRNA-THAP9 antisense RNA 1(THAP9-AS1) (fold change:3.7), lncRNACH507-513H4.3 (fold change:3.8) and lncRNA-RP4794H19.1 (fold change:1.8). QPCR results were consistent with RNA sequencing data(Table 1). The lncRNAs in NPC reported in former research also credited our RNA-seq data(Table 2). QPCR results were shown in Figure 4.

Table 1. Primers used for qPCR analysis of IncRNA levels.

\begin{tabular}{|c|c|c|c|}
\hline LncRNA & Primer & $\begin{array}{l}\text { Expressi } \\
\text { on }\end{array}$ & $\begin{array}{l}\text { Product } \\
\text { Length (bp) }\end{array}$ \\
\hline NR2F2-AS1 & $\begin{array}{l}\text { F: GGCTTGGTTGGACCGTACTC } \\
\text { R:ACTGCCTGCCACTCTTGTGA }\end{array}$ & Down & 121 \\
\hline FAM95C & $\begin{array}{l}\text { F: CCTCATCCAGAGCAGGACAA } \\
\text { R: GCCTGCATTAGCATCTGTGC }\end{array}$ & Down & 128 \\
\hline LINC01106 & $\begin{array}{l}\text { F:GAGAGAGGAATGGCTGCATGT } \\
\text { R:TCAGGAGGTTGCAGGTTGAC }\end{array}$ & Down & 121 \\
\hline CH507-513H4.6 & $\begin{array}{l}\text { F: CATGCCAGAGTCTCGTTCGTT } \\
\text { R: GGACACGGACAGGATTGACA }\end{array}$ & Up & 125 \\
\hline THAP9-AS1 & $\begin{array}{l}\text { F: GAAGGTCCACAGCCAGTTCC } \\
\text { R: CGCATTGCTGTAGGCATAGG }\end{array}$ & Up & 121 \\
\hline CH507-513H4.3 & $\begin{array}{l}\text { F:TTGCTCAATCTCGGGTGGCT } \\
\text { R:TGGTGGAGCGATTTGTCTGG }\end{array}$ & Up & 138 \\
\hline RP4-794H19.1 & $\begin{array}{l}\text { F:CCTTCCGCCTTGGCAAAGAT } \\
\text { R:TGTGGGGTGAAGGTCTGGTT }\end{array}$ & UP & 120 \\
\hline
\end{tabular}
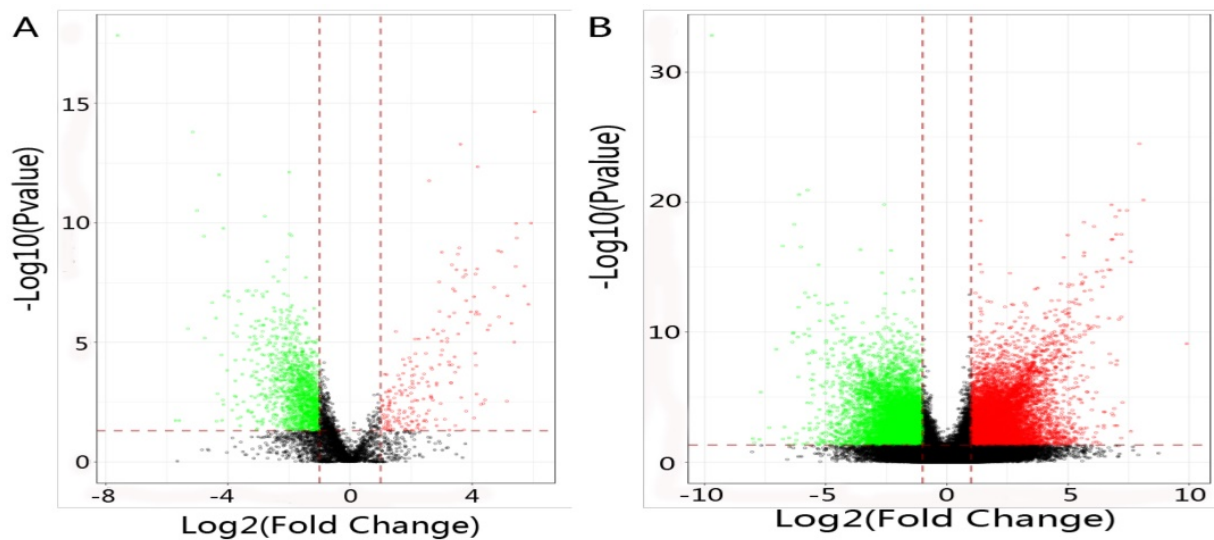

Figure 2: (A) The volcano plot of differential expressions of IncRNAs in NPC and normal tissues. Dark spot: $\log 2$ (fold change) <1, P value $>0.05$; Red spot: log2(fold change) $\geq 1, P$ value $\leq 0.05$; Green spot: log2(fold change) $\leq-1$, P value $\leq 0.05$. (B) The volcano plot of differential expressions of mRNAs in NPC and normal tissues. Dark spot: $\log 2$ (fold change) $<1, P$ value $>0.05$; Red spot: $\log 2$ (fold change) $\geq 1, P$ value $\leq 0.05$; Green spot: $\log 2$ (fold change) $\leq-1, P$ value $\leq 0.05$. 

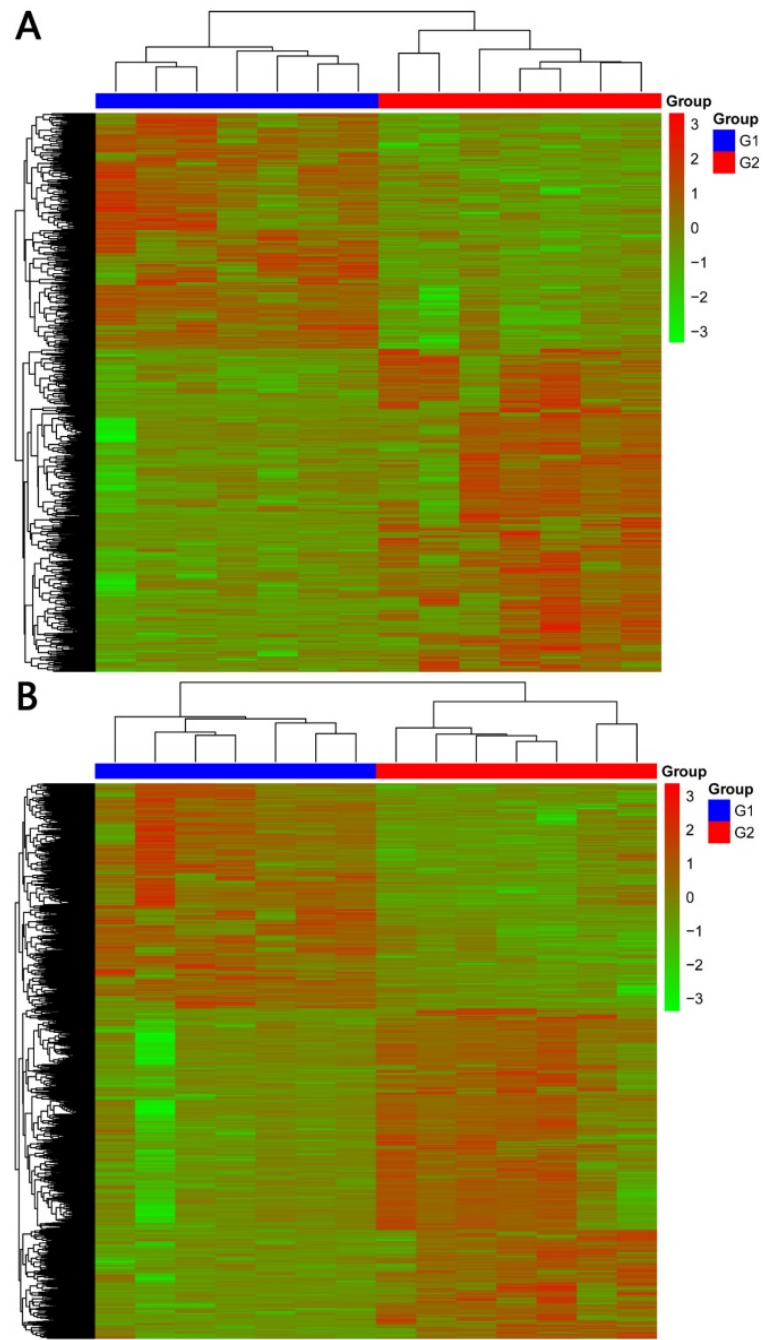

Figure 3: (A) Heat maps of differential expressions of and hierarchical clustering of IncRNAsin NPC and normal tissues. (B) Heat maps of differential expressions of and hierarchical clustering of mRNAs in NPC and normal tissues.

\section{Differential expressions of IncRNAs and Cis-regulation and trans-regulation genes co-expression networks}

We defined the chromosomal genes (co-expression mRNA mapped), which were $100 \mathrm{~kb}$ upstream or downstream of differentially expressed lncRNAs, as potential lncRNA cis-regulatory genes. Totally, there were 1895 differentially expressed lncRNAs with 4848 cis-regulatory genes. Among them, LA16c-313D11.9 had 231 cis-regulatory genes(the most). One differentially expressed lncRNA for one cis-regulatory gene number was 59. One cis-regulatory gene for one differentially expressed lncRNA was 566.

Pearson correlation coefficient $\left(R^{2} \geq 0.95\right)$ was applied to predict trans-regulatory genes. In total, there were 1284 differentially expressed lncRNAs with 6437 trans-regulatory genes. Among them, AC000123.4 had 577 trans-regulatory genes(the most).

One differentially expressed lncRNA for one transregulatory gene number was 2263. One transregulatory genes for one differentially expressed lncRNA was 566. The networks of cis-regulation and trans-regulation were illuminated in Figure 5.

Table 2. LncRNAs reported in NPC in former research.

\begin{tabular}{|c|c|c|c|}
\hline LncRNA & Location & Expression & Fold change \\
\hline xist[21] & $\begin{array}{l}\text { Chromosome X } \\
73820651-73852753\end{array}$ & UP & 1.5 \\
\hline Hotair[20] & $\begin{array}{l}\text { Chromosome } 12 \\
53962308-53974956\end{array}$ & UP & 1.2 \\
\hline CASC9[23] & $\begin{array}{l}\text { Chromosome } 8 \\
75223117-75278889\end{array}$ & UP & 1.6 \\
\hline MEG3[22] & $\begin{array}{l}\text { Chromosome } 14 \\
100779410-100861031\end{array}$ & DOWN & 2.6 \\
\hline EWSAT1[24] & $\begin{array}{l}\text { Chromosome } 15 \\
69072926-69095820\end{array}$ & UP & 1.7 \\
\hline
\end{tabular}
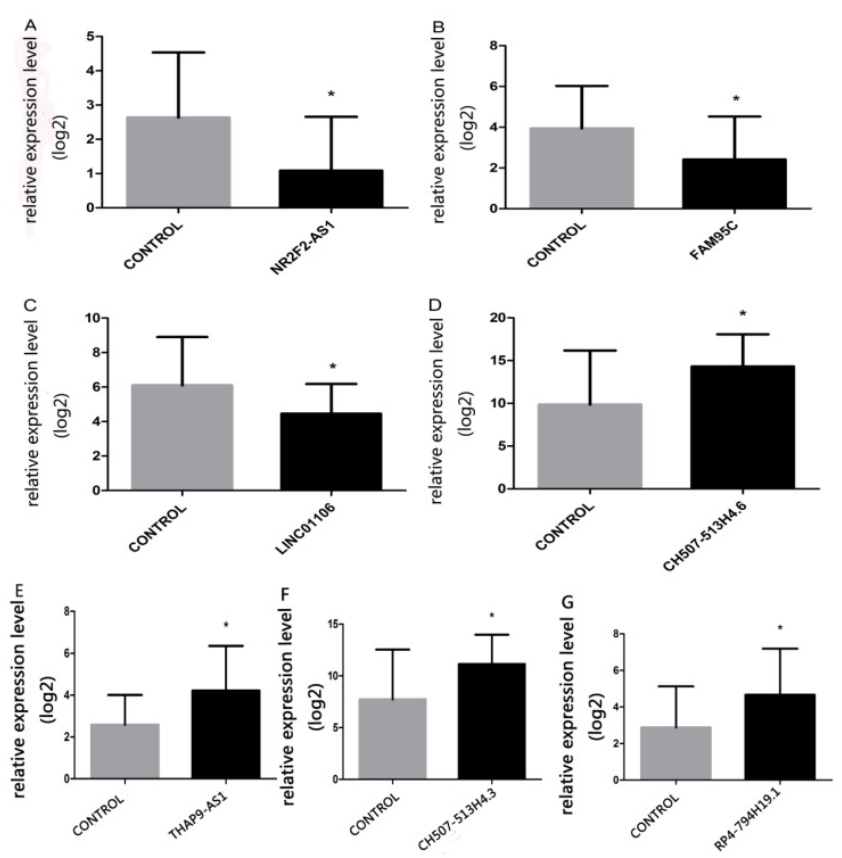

Figure 4: The relative-expression levels of seven IncRNAs (A, NR2F2-AS1; B, FAM95C; C, LINC01 106; D, CH507-513H4.6; E, THAP9-AS1, F, CH507-513H4.3; G, RP4-794H19.1) in NPC and normal tissues. Kruskal-Wallis $\mathrm{H}$ test was applied, ${ }^{*} \mathrm{p}<0.05$.

\section{Gene ontology (GO) enrichment and pathway analysis}

GO enrichment analysis was conducted by TopGO software, and associated with Fisher Exact Test. The results suggested that the significant functions mainly focused on embryonic skeletal system development, embryonic skeletal system morphogenesis, ATP-dependent microtubule motor activity and regulation of gene expression in lncRNAs cis-regulation genes between NPC and normal tissues. As for lncRNAs trans-regulation genes, they laid in intracellular part, intracellular and nuclear part. The detailed results were presented in Figure 6. A and Figure 7. A. 

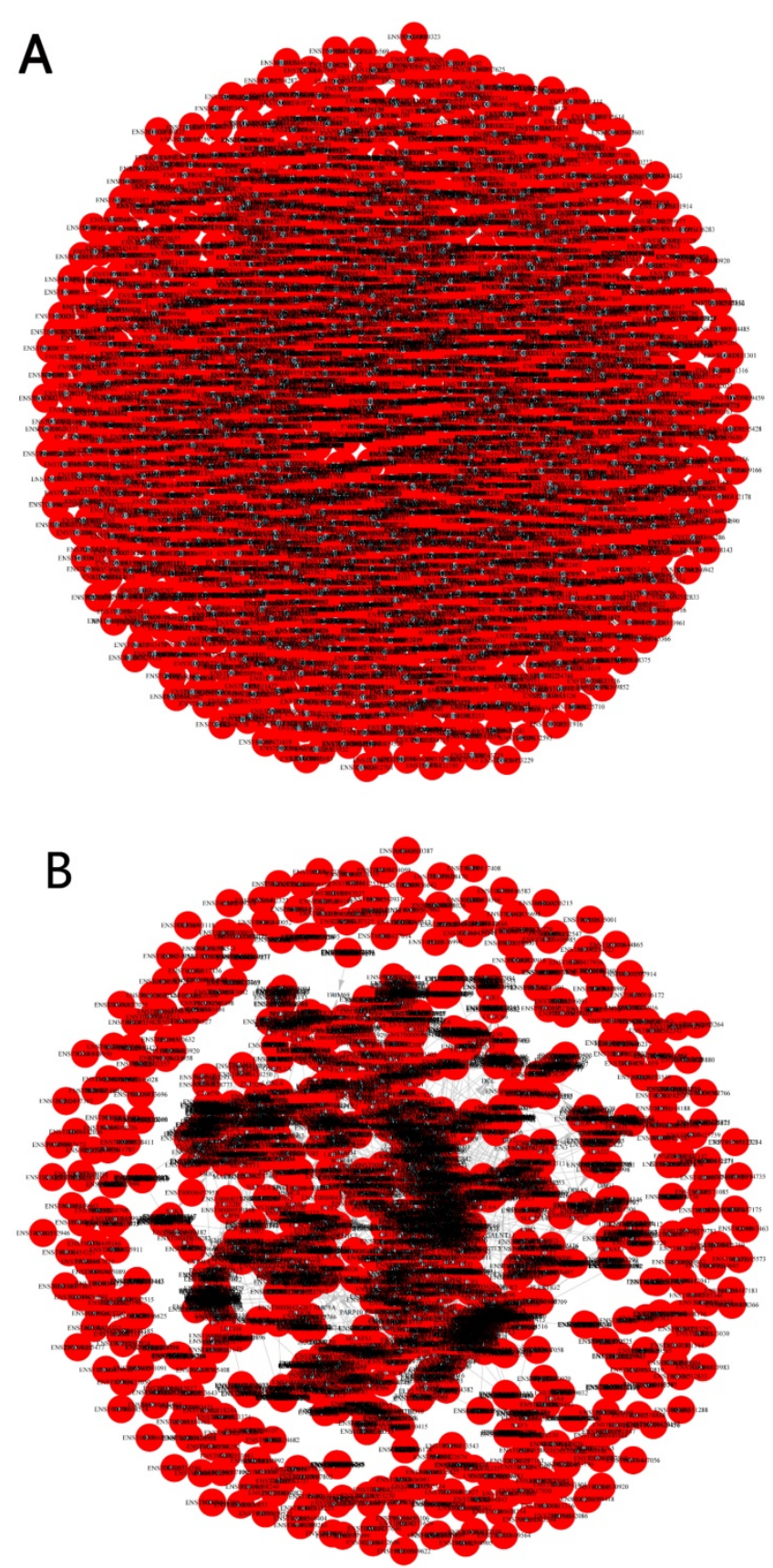

Figure 5: (A) Cis-regulation of the networks. Red spot represented differential expression of IncRNA. Blue spot represented cis-regulation gene. (B) Trans-regulation of the networks. Red spot represented differential expression of IncRNA. Blue spot represented trans-regulation gene.

KEGG pathway analysis concluded that the most significant pathways of lncRNAs cis-regulation genes were Proteoglycans in cancer, Vascular smooth muscle contraction and Glutamatergic synapse, while Proteasome, Spliceosome and Huntington's disease were in lncRNAs trans-regulation genes. The rest were demonstrated in Figure 6. B and Figure 7. B.

\section{Discussion}

In 2015, there were sixty thousand new NPC cases reported in China[19]. For NPC patients usually were diagnosed at late stage, and it's a challenge to determine the disease at an early stage. Here, we resorted to the next-generation sequencing technology in 7 cases of NPC tissues and 7 cases of nasopharyngeal normal tissues. 2192 differentially expressed lncRNAs were found, which had the making of potential biomarkers for early-stage diagnosis, progression and prognosis[20]. Moreover, 4248 novel lncRNAs were obtained, and might tremendously enrich the human lncRNA pool.

There was an interesting finding when we mapped differentially expressed lncRNAs to human chromosomes. Y- chromosome had no differentially expressed lncRNAs in NPC and normal tissues(Figure 8), meanwhile, no such studies have been issued. According to demographic trends, men were two to three fold more likely to acquire NPC than women were[1]. Maybe Y- chromosome was short of some suppressor lncRNAs inflicting a higher morbidity compared with women in NPC.

Seven qPCR results were credible based on our work, and several reported studies also supported it. Increased $X$ inactive specific transcript (XIST) expression was associated with poor prognosis and stunted cell growth[21]. HOX transcript antisense RNA(Hotair) might play an oncogenic role in NPC progression, and its knockdown attenuated NPC cell growth and angiogenesis[20]. Both DNA copy number loss and aberrant promoter methylation led to maternally expressed 3(MEG3) inactivation. As a tumor suppressor, which could be significantly inhibited in cell proliferation, colony formation[22]. Overexpressed cancer susceptibility 9 (CASC9) promoted the glycolysis and tumorigenesis of NPC cells via activating hypoxia inducible factor 1 alpha subunit (HIF1alpha)[23]. Ewing sarcoma associated transcript 1(EWSAT1) could up-regulate the expressions of miR-326/330-5p clusters targeted gene cyclin D1 through a competitive 'sponge' of miR-326/330-5p clusters, which might promote the development of NPC[24].

However, only few known lncRNAs had functional annotations. The methods for lncRNAs function prediction always investigated their correlated protein coding genes and related biological pathways[25]. It also had been proved that lncRNAs function through cis-regulation of nearby protein coding genes was a common mechanism[26]. Only a few lncRNAs were refined as cis-regulators, while the majority of functionally annotated ones were trans-regulators[27]. Therefore, we divided the differentially expressed lncRNAs cis-regulation or trans-regulation genes into two categories to explore the potential target genes, GO enrichment and KEGG 
pathways analysis. 62 lncRNAs trans-regulated genes were involved in the EBV infection pathway in our study (Figure 7B), as CD44[28] and interleukin 1 receptor associated kinase 1(IRAK1)[29] (Table S1). In our work, we defined $100 \mathrm{~kb}$ distance as a criterion between lncRNAs and cis-regulated genes. Jun proto-oncogene(JUN), which was located 98542b downstream to LncRNA RP4-794H19.1, was enriched in cancers and involve in Tumor Necrosis Factor (TNF) signaling pathway. For example, the expression levels of JUN family members were positively correlated to the cell proliferation in diffuse large B-cell lymphomas[30]. Furthermore, NAG7 through the activity of JUN pathways could promote the invasion in NPC[31]. For good measure, the EBV-encoded EBNA1 regulated the JUN transcription factor pathway in NPC and increased angiogenesis in vitro[32]. Our results underpinned that lncRNA RP4-794H19.1 in relation to JUN might play a key role in NPC. However our work strongly depended on the theoretically computerized calculation, lacking further numerous practice validation. These findings broadened the lncRNAs landscape of NPC and shed light on the roles of these lncRNAs, which might be conducive to the comprehensive management of NPC.
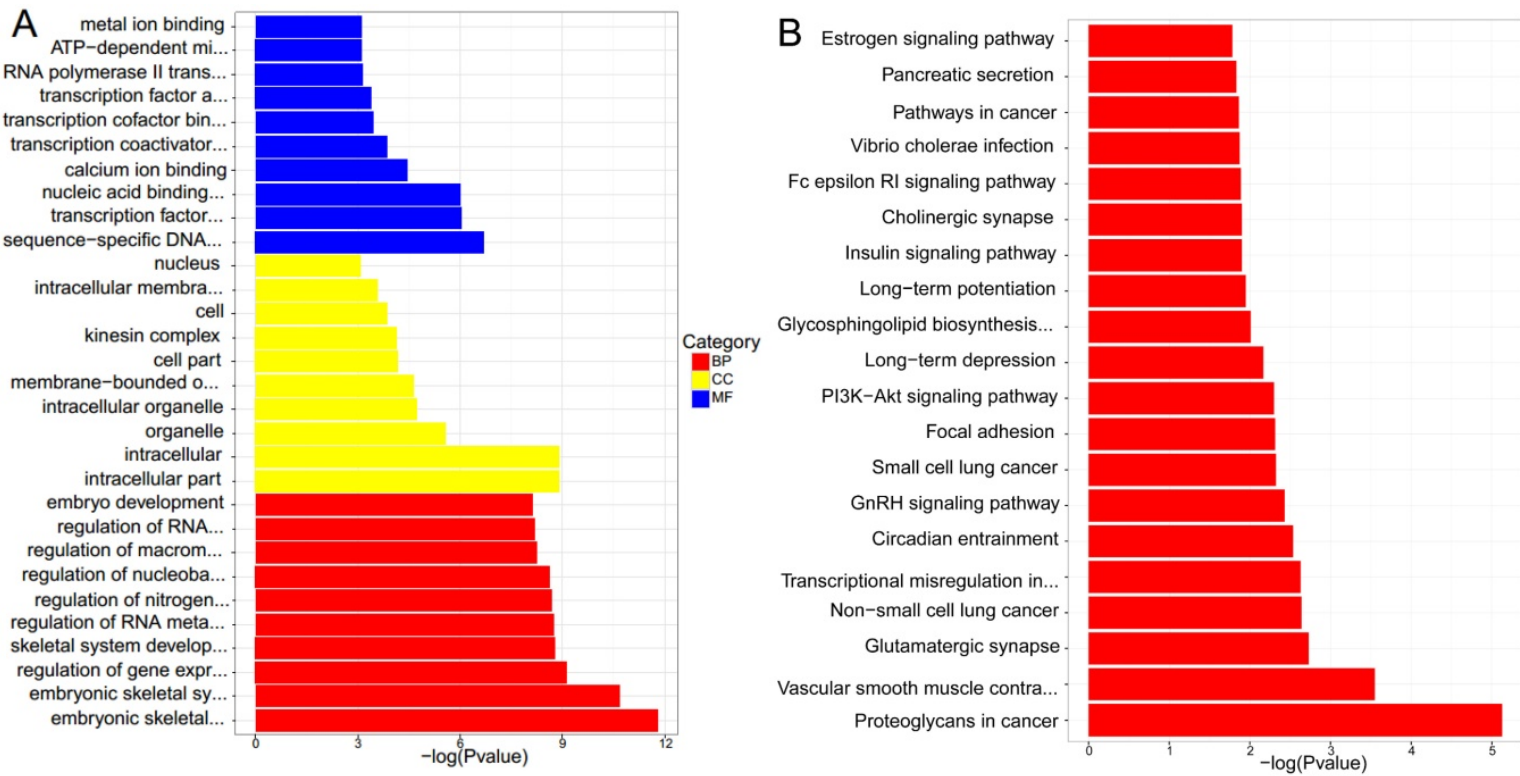

Figure 6: (A) GO enrichmentanalysis of differential expressions of IncRNAs cis-regulation genes. (B) KEGG pathway analysis of differential expressions of IncRNAs cis-regulation genes.
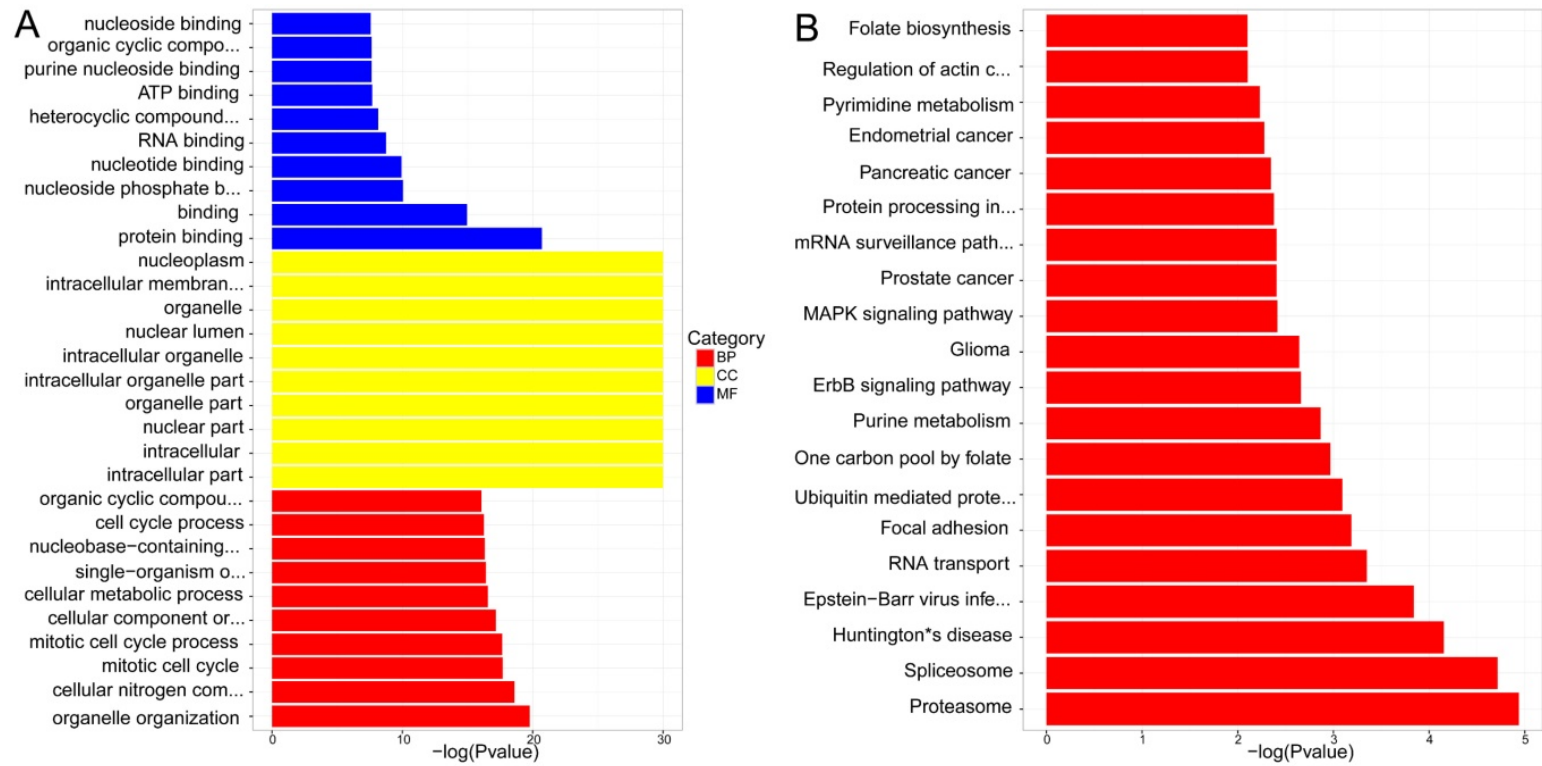

Figure 7: (A) GO enrichment of differential expressions of IncRNAs trans-regulation genes (B) KEGG pathway analysis of differential expressions of IncRNAs trans-regulation genes. 


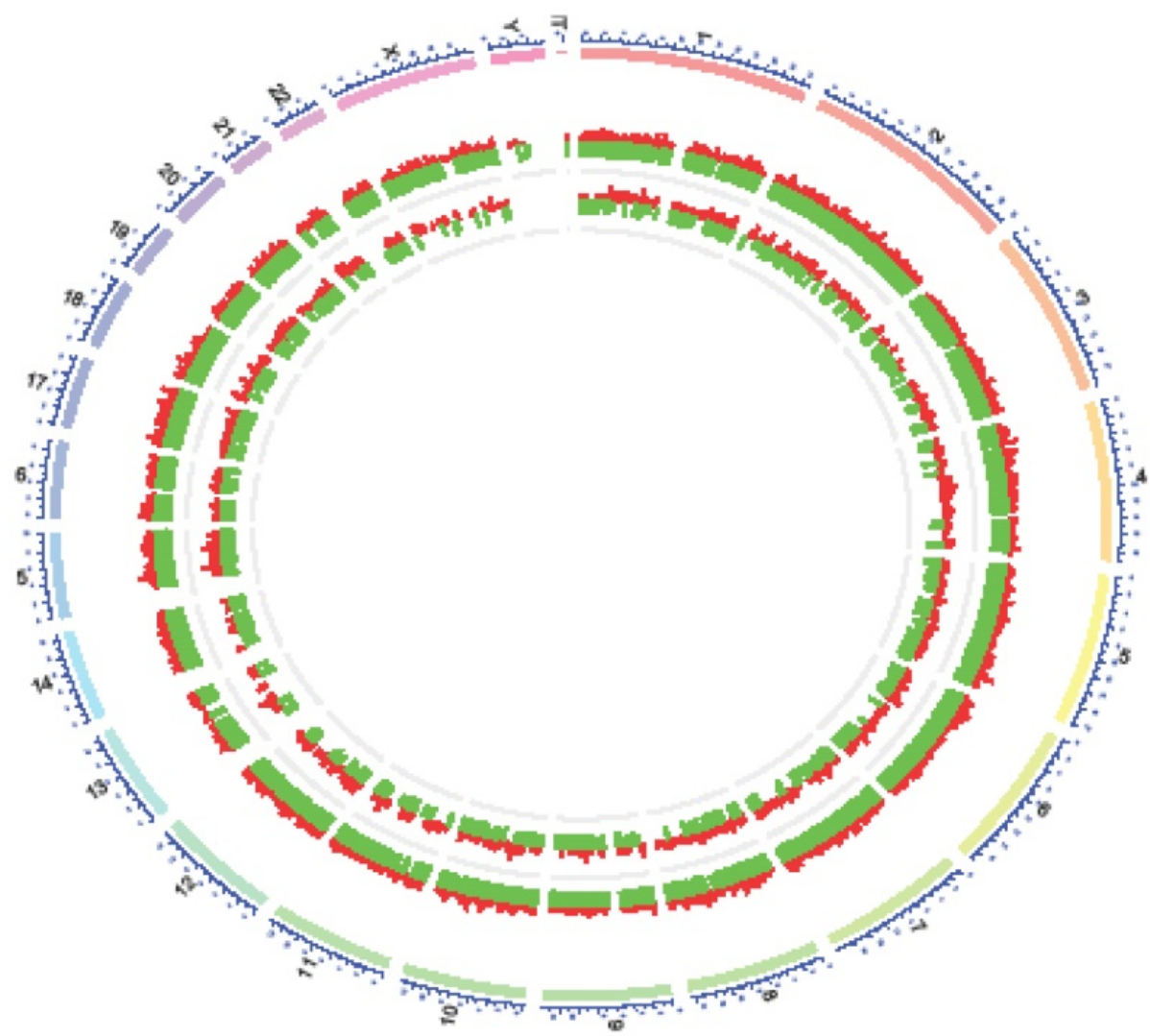

Figure 8: Distribution of differential expressions of IncRNAs and mRNAs along each chromosome. The chromosome constitution (outer circle, depicted in blue), distribution of differential expressions of mRNAs (middle circle, depicted in red: up-regulation, green: down-regulation) and distribution of differential expressionsof IncRNAs (inner circle, depicted in red: up-regulation, green: down-regulation).

\section{Abbreviations}

lncRNAs: long non-coding RNAs; qPCR: Real-time Quantitative PCR; JUN: Jun proto-oncogene; TNF: Tumor Necrosis Factor; NPC: nasopharyngeal carcinoma; EBV: Epstein-Barr virus; ORF: open reading frame; ENCODE: Encyclopedia of DNA Elements; RIP RNA: Immunoprecipitation; KEGG: the Kyoto Encyclopedia ofGenes and Genomes; COG: Clusters of Orthologous Groups; NR2F2-AS1: lncRNA-NR2F2antisense RNA 1; FAM95C: lncRNA-family with sequencesimilarity 95 member C; LINC01106: IncRNA- long intergenic nonprotein coding RNA 1106; THAP9-AS1: lncRNA-THAP9 antisense RNA 1; Gene ontology: GO; XIST X: inactive specific transcript; Hotair: HOX transcript antisense RNA; MEG3: maternally expressed 3; CASC9: Overexpressed cancer susceptibility 9; HIF1alpha: hypoxia inducible factor 1 alphasubunit; EWSAT1: Ewing sarcoma associated transcript 1; IRAK1: interleukin 1 receptor associated kinase 1.

\section{Supplementary Material}

Supplementary table S1.

http:/ / www.jcancer.org/v09p1943s1.xls
Supplementary table S2.

http://www.jcancer.org/v09p1943s2.xls

Supplementary table S3.

http://www.jcancer.org/v09p1943s3.xls

Supplementary table $S 4$.

http:/ / www.jcancer.org/v09p1943s4.xls

Supplementary table S5.

http:/ / www.jcancer.org/v09p1943s5.xls

Supplementary table S6.

http://www.jcancer.org/v09p1943s6.xls

Supplementary table $S 7$.

http://www.jcancer.org/v09p1943s7.xls

Supplementary table $S 8$.

http://www.jcancer.org/v09p1943s8.xls

Supplementary table $S 9$.

http://www.jcancer.org/v09p1943s9.xls

\section{Acknowledgements}

This work was supported by the National Natural Science Foundation of China (No.81372516), and Hunan Provincial Natural Science Foundation of China (No. 2016JJ5013).

\section{Competing Interests}

The authors have declared that no competing interest exists. 


\section{References}

1. Chua MLK, Wee JTS, Hui EP, Chan ATC. Nasopharyngeal carcinoma. The Lancet. 2016; 387(10022):1012-24.

2. Xu ZX, Lin ZX, Fang JY, Wu KS, Du PL, Zeng Y, et al. Mortality Characteristic and Prediction of Nasopharyngeal Carcinoma in China from 1991 to 2013. Asian Pacific Journal of Cancer Prevention. 2015; 16(15):6729-34.

3. He R, Hu Z, Wang Q, Luo W, Li J, Duan L, et al. The role of long non-coding RNAs in nasopharyngeal carcinoma: As systemic review. Oncotarget. 2017; 8(9):16075-83.

4. Huarte M. The emerging role of IncRNAs in cancer. Nature Medicine. 2015;21(11):1253-61.

5. Ponting CP, Oliver PL, Reik W. Evolution and functions of long noncoding RNAs. Cell. 2009; 136(4):629-41.

6. Derrien T, Johnson R, Bussotti G, Tanzer A, Djebali S, Tilgner H, et al. The GENCODE v7 catalog of human long noncoding RNAs: Analysis of their gene structure, evolution, and expression. Genome Research. 2012; 22(9):1775-89.

7. Jalali S, Gandhi S, Scaria V. Navigating the dynamic landscape of long noncoding RNA and protein-coding gene annotations in GENCODE. Human Genomics. 2016; 10(1):35.

8. De Clara E, Gourvest M, Ma H, Vergez F, Tosolini M, Dejean S, et al. Long non-coding RNA expression profile in cytogenetically normal acute myeloid leukemia identifies a distinct signature and a new biomarker in NPM1-mutated patients. Haematologica. 2017; 102(10):1718-26.

9. Malouf GG, Zhang J, Yuan Y, Comperat E, Roupret M, Cussenot O, et al. Characterization of long non-coding RNA transcriptome in clear-cell renal cell carcinoma by next-generation deep sequencing. Molecular Oncology. 2015; 9(1):32-43

10. Wang Y, Zhang H, Li X, Chen W. Differential expression profile analysis of IncRNA UCA1alpha regulated mRNAs in bladder cancer. Journal of Cellular Biochemistry. 2017; [Epub ahead of print].

11. Qiu X, Jia B, Sun X, Hu W, Chu H, Xu S, et al. The Critical Role of Long Noncoding RNA in Osteogenic Differentiation of Human Bone Marrow Mesenchymal Stem Cells. Biomed Res Int. 2017; 2017:5045827.

12. Yang QQ, Deng YF. Genome-wide analysis of long non-coding RNA in primary nasopharyngeal carcinoma by microarray. Histopathology. 2015; 66(7):1022-30.

13. Xing Z, Lin A, Li C, Liang K, Wang S, Liu Y, et al. IncRNA directs cooperative epigenetic regulation downstream of chemokine signals. Cell. 2014; 159(5):1110-25.

14. Xiang JF, Yin QF, Chen T, Zhang Y, Zhang XO, Wu Z, et al. Human colorectal cancer-specific CCAT1-L IncRNA regulates long-range chromatin interactions at the MYC locus. Cell Research. 2014; 24(5):513-31.

15. Taniue K, Kurimoto A, Sugimasa H, Nasu E, Takeda Y, Iwasaki K, et al. Long noncoding RNA UPAT promotes colon tumorigenesis by inhibiting degradation of UHRF1. Proceedings of the National Academy of Sciences of the United States of America. 2016; 113(5):1273-8.

16. Tang Y, He Y, Shi L, Yang L, Wang J, Lian Y, et al. Co-expression of AFAP1-AS1 and PD-1 predicts poor prognosis in nasopharyngeal carcinoma. Oncotarget. 2017; 8(24):39001-11.

17. Ren S, Li G, Liu C, Cai T, Su Z, Wei M, et al. Next generation deep sequencing identified a novel lncRNA n375709 associated with paclitaxel resistance in nasopharyngeal carcinoma. Oncology Reports. 2016; 36(4):1861-7.

18. Yoshida K, Sanada M, Ogawa S. Deep sequencing in cancer research. Japanese Journal of Clinical Oncology. 2013; 43(2):110-5.

19. Chen W, Zheng R, Baade PD, Zhang S, Zeng H, Bray F, et al. Cancer statistics in China, 2015. CA: A Cancer Journal for Clinicians. 2016; 66(2):115-32.

20. Fu WM, Lu YF, Hu BG, Liang WC, Zhu X, Yang HD, et al. Long noncoding RNA Hotair mediated angiogenesis in nasopharyngeal carcinoma by direct and indirect signaling pathways. Oncotarget. 2016; 7(4):4712-23.

21. Song P, Ye LF, Zhang C, Peng T, Zhou XH. Long non-coding RNA XIST exerts oncogenic functions in human nasopharyngeal carcinoma by targeting miR-34a-5p. Gene. 2016; 592(1):8-14.

22. Chak WP, Lung RW, Tong JH, Chan SY, Lun SW, Tsao SW, et al. Downregulation of long non-coding RNA MEG3 in nasopharyngeal carcinoma. Molecular Carcinogenesis. 2017; 56(3):1041-54

23. Su X, Li G, Liu W. The Long Noncoding RNA Cancer Susceptibility Candidate 9 Promotes Nasopharyngeal Carcinogenesis via Stabilizing HIF1alpha. DNA and Cell Biology. 2017; 36(5):394-400.

24. Song $\mathrm{P}$, Yin SC. Long non-coding RNA EWSAT1 promotes human nasopharyngeal carcinoma cell growth in vitro by targeting miR-326/-330-5p. Aging. 2016; 8(11):2948-60.

25. Guttman M, Amit I, Garber M, French C, Lin MF, Feldser D, et al. Chromatin signature reveals over a thousand highly conserved large non-coding RNAs in mammals. Nature. 2009; 458(7235):223-7.

26. Nagel D, Vincendeau M, Eitelhuber AC, Krappmann D. Mechanisms and consequences of constitutive NF-kappaB activation in B-cell lymphoid malignancies. Oncogene. 2014; 33(50):5655-65

27. Young RM, Shaffer AL, 3rd, Phelan JD, Staudt LM. B-cell receptor signaling in diffuse large B-cell lymphoma. Seminars in Hematology. 2015; 52(2):77-85.

28. Janisiewicz AM, Shin JH, Murillo-Sauca O, Kwok S, Le QT, Kong C, et al. $\mathrm{CD} 44+$ cells have cancer stem cell-like properties in nasopharyngeal carcinoma. Int Forum Allergy Rh. 2012; 2(6):465-70.

29. Luftig M, Prinarakis E Fau - Yasui T, Yasui T Fau - Tsichritzis T, Tsichritzis T Fau - Cahir-McFarland E, Cahir-McFarland E Fau - Inoue J-I, Inoue J Fau -
Nakano $\mathrm{H}$, et al. Epstein-Barr virus latent membrane protein 1 activation of NF-kappaB through IRAK1 and TRAF6. Proc Natl Acad Sci USA. 2003; 200(26):15595-15600. (0027-8424 (Print)).

30. Papoudou-Bai A, Goussia A, Batistatou A, Stefanou D, Malamou-Mitsi V, Kanavaros P. The expression levels of JunB, JunD and p-c-Jun are positively correlated with tumor cell proliferation in diffuse large B-cell lymphomas. Leukemia \& Lymphoma. 2016; 57(1):143-50.

31. Huang C, Wu MH, Tang YL, Li XL, Ouyang J, Xiao L, et al. NAG7 Promotes Human Nasopharyngeal Carcinoma Invasion Through Inhibition of Estrogen Receptor Alpha and Up-Regulation of JNK2/AP-1/MMP1 Pathways. J Cell Physiol. 2009; 221(2):394-401.

32. O'Neil JD, Owen TJ, Wood VH, Date KL, Valentine R, Chukwuma MB, et al. Epstein-Barr virus-encoded EBNA1 modulates the AP-1 transcription factor pathway in nasopharyngeal carcinoma cells and enhances angiogenesis in vitro. The Journal of General Virology. 2008; 89(Pt 11):2833-42. 